\title{
Effect of elevated temperature on membrane lipid saturation in Antarctic notothenioid fish
}

\author{
Vanita C Malekar ${ }^{\text {Corresp.. }}{ }^{1}$ ， James D Morton ${ }^{1}$, Richard N Hider ${ }^{1}$ ， Robert H Cruickshank ${ }^{2}$, Simon Hodge ${ }^{3}$, \\ Victoria J Metcalf ${ }^{4}$ \\ ${ }^{1}$ Department of Wine, Food and Molecular Biosciences, Faculty of Agriculture and Life Sciences, Lincoln University, Christchurch, New Zealand \\ 2 Department of Ecology, Faculty of Agriculture and Life Sciences, Lincoln University, Christchurch, New Zealand \\ 3 Department of Agricultural Sciences, Faculty of Agriculture and Life Sciences, Lincoln University, Christchurch, New Zealand \\ 4 Office of the Prime Minister's Chief Science Advisor, University of Auckland, Auckland, New Zealand \\ Corresponding Author: Vanita C Malekar \\ Email address: Vanita.Malekar@lincolnuni.ac.nz
}

Homeoviscous adaptation (HVA) is a key cellular response by which fish protect their membranes against thermal stress. We investigated evolutionary HVA (long time scale) in Antarctic and non-Antarctic fish. Membrane lipid composition was determined for four Perciformes fish: two closely related Antarctic notothenioid species (Trematomus bernacchii and Pagothenia borchgrevinki); a diversified related notothenioid Antarctic icefish (Chionodraco hamatus); and a New Zealand species (Notolabrus celidotus). The membrane lipid compositions were consistent across the three Antarctic species and these were significantly different from that of the New Zealand species. Furthermore, acclimatory HVA (short time periods with seasonal changes) was investigated to determine whether stenothermal Antarctic fish, which evolved in the cold, stable environment of the Southern Ocean, have lost the acclimatory capacity to modulate their membrane saturation states, making them vulnerable to anthropogenic global warming. We compared liver membrane lipid composition in two closely related Antarctic fish species acclimated at $0{ }^{\circ} \mathrm{C}$ (control temperature), $4{ }^{\circ} \mathrm{C}$ for a period of 14 days in Trematomus bernacchii and 28 days for Pagothenia borchgrevinki, and $6{ }^{\circ} \mathrm{C}$ for 7 days in both species. Thermal acclimation at $4{ }^{\circ} \mathrm{C}$ did not result in changed membrane saturation states in either Antarctic species. Despite this, membrane functions were not compromised, as indicated by declining serum osmolality, implying positive compensation by enhanced hypoosmoregulation. Increasing the temperature to $6{ }^{\circ} \mathrm{C}$ did not change the membrane lipids of $P$. borchgrevinki. However, in $T$. bernacchii, thermal acclimation at $6{ }^{\circ} \mathrm{C}$ resulted in an increase of membrane saturated fatty acids and a decline in unsaturated fatty acids. This is the first study to show a homeoviscous response to higher temperatures in an Antarctic fish, although for only one of the two species examined. 


\section{Effect of elevated temperature on membrane lipid saturation 2 in Antarctic notothenioid fish}

4 Vanita C. Malekar ${ }^{*}$, James D. Morton ${ }^{1}$, Richard N. Hider ${ }^{1}$, Robert H. Cruickshank², Simon

5 Hodge $^{3}$, Victoria J. Metcalf ${ }^{4}$

$6{ }^{1}$ Department of Wine, Food and Molecular Biosciences, Faculty of Agriculture and Life

7 Sciences, Lincoln University, Lincoln, New Zealand

8 2Department of Ecology, Faculty of Agriculture and Life Sciences, Lincoln University, Lincoln, 9 New Zealand

$10{ }^{3}$ Department of Agricultural Sciences, Faculty of Agriculture and Life Sciences, Lincoln

11 University, Lincoln, New Zealand

$12{ }^{4}$ Office of the Prime Minister's Chief Science Advisor, Auckland, New Zealand

$13 *$ Corresponding Author

14 Vanita.Malekar@lincolnuni.ac.nz 


\section{Abstract}

16 Homeoviscous adaptation (HVA) is a key cellular response by which fish protect their membranes against thermal stress. We investigated evolutionary HVA (long time scale) in Antarctic and nonAntarctic fish. Membrane lipid composition was determined for four Perciformes fish: two closely related Antarctic notothenioid species (Trematomus bernacchii and Pagothenia borchgrevinki); a diversified related notothenioid Antarctic icefish (Chionodraco hamatus); and a New Zealand species (Notolabrus celidotus). The membrane lipid compositions were consistent across the three Antarctic species and these were significantly different from that of the New Zealand species. Furthermore, acclimatory HVA (short time periods with seasonal changes) was investigated to determine whether stenothermal Antarctic fish, which evolved in the cold, stable environment of the Southern Ocean, have lost the acclimatory capacity to modulate their membrane saturation states, making them vulnerable to anthropogenic global warming. We compared liver membrane lipid composition in two closely related Antarctic fish species acclimated at $0{ }^{\circ} \mathrm{C}$ (control temperature), $4{ }^{\circ} \mathrm{C}$ for a period of 14 days in Trematomus bernacchii and 28 days for Pagothenia borchgrevinki, and $6{ }^{\circ} \mathrm{C}$ for 7 days in both species. Thermal acclimation at $4{ }^{\circ} \mathrm{C}$ did not result in changed membrane saturation states in either Antarctic species. Despite this, membrane functions were not compromised, as indicated by declining serum osmolality, implying positive compensation by enhanced hypo-osmoregulation. Increasing the temperature to $6{ }^{\circ} \mathrm{C}$ did not change the membrane lipids of $P$. borchgrevinki. However, in $T$. bernacchii, thermal acclimation at $6{ }^{\circ} \mathrm{C}$ resulted in an increase of membrane saturated fatty acids and a decline in unsaturated fatty acids. This is the first study to show a homeoviscous response to higher temperatures in an Antarctic fish, although for only one of the two species examined. 


\section{Introduction}

38 When the cell membranes of fish and other poikilothermic organisms are subjected to thermal change, modifications in membrane lipids and fluidity may occur in order to maintain membrane properties and functions. Altered membrane composition in response to lower or higher temperature, known as homeoviscous adaptation (HVA), is observed across all poikilotherms (Hazel \& Williams 1990). HVAs that occur over short periods during the lifetime of an individual are acclimatory adaptive changes; e.g. as observed in eurythermic temperate fish, which possess a broad thermal adaptable range. Acclimation to lower temperature results in increases in the proportion of unsaturated fatty acids in membranes, to allow optimal membrane fluidity to be maintained. This suggests a protective role of the homeoviscous response in short-term acclimation (Skalli et al. 2006; Snyder et al. 2012). In contrast to these acclimatory adaptive changes observed in non-Antarctic fish, the HVA response in Antarctic fish can be a long-term evolutionary adaptive change in response to the low temperatures experienced in the Southern Ocean. Antarctic notothenioid fish, for example, display an evolutionary adaptive mechanisms where their cell membranes possess an increased proportion of unsaturated fatty acids (Hazel 1995).

Marine Antarctic ectotherms are stenothermal as they experience negligible seasonal variation ($1.9{ }^{\circ} \mathrm{C}$ to approximately $1.8{ }^{\circ} \mathrm{C}$ ), resulting in limited ability to adapt to temperature variation (Somero 2010), and increased vulnerability to climate change effects (Aronson et al. 2011). In temperate and tropical latitudes, marine ectotherms experience much greater seasonal variation in temperature, and are correspondingly more thermally tolerant or eurythermal (Aronson et al. 2011). Evolution of stenotherms in a "stable ice bath" has involved many critical changes in the genome that facilitate life in extreme cold, such as losses of certain traits that are no longer required (Pörtner et al. 2007). Loss of heat shock response (HSR) has been observed in Antarctic fish (Hofmann et al. 2000), resulting in extreme stenothermality due to an incapability to minimise damage to their protein pool caused by elevated temperatures (Podrabsky 2009). Homeoviscous adaptation to the constant cold temperatures of the Southern Ocean is one of the key evolutionary adaptive changes in Antarctic notothenioid fish, but it is not known whether they have the capacity to change their membrane saturation states in response to warmer temperatures, as one trade-off cost for stenothermality may be reduced adaptive capacity. 
Anthropogenic global warming (AGW) poses a threat to polar and especially stenothermal polar species, and there is a need to determine the impact of warmer temperatures on the acclimatory responses of these species, including cellular membrane remodelling. There is evidence that Antarctic fish may not exhibit an acclimatory HVA response to transient temperature changes, as unchanged membrane lipid saturation states were observed in Antarctic fish (Trematomus bernacchii and T. newnesi) acclimated to a temperature of $4{ }^{\circ} \mathrm{C}$ for five weeks (Gonzalez-Cabrera et al. 1995). However, these fish showed positive compensation with an increase in the $\mathrm{Na}+/ \mathrm{K}(+)-$ ATPase activity and a decline in the serum osmolality, implying that membrane functions were not compromised in spite of the unmodified saturation states. Temperature is also a major determinant of membrane-cholesterol levels, with high membrane cholesterol observed in warmacclimated marine copepods (Hassett \& Crockett 2009). Levels of cholesterol have been shown to increase at higher temperatures resulting in reduced membrane fluidity (Crockett 1998). It is not known whether Antarctic fish share this adaptive membrane cholesterol change in response to increased temperature.

This study aimed to investigate both evolutionary and acclimatory HVA responses in Antarctic fish, and brings together existing evidence, along with new experimental data, to understand the evolutionary adaptive response associated with cold tolerance. Firstly, to investigate evolutionary adaptive HVA in cold-water fish, we established the normal lipid saturation profile of liver tissue from three Antarctic fish species collected in their normal physiological temperature for comparison with a non-Antarctic New Zealand fish species. More specifically, we compared liver membrane lipid profiles of two closely related Antarctic species,Pagothenia borchgrevinki (PB) and Trematomus bernacchii (TB), and a more distantly related icefish species Chionodraco hamatus $(\mathrm{CH})$ of Antarctic notothenioid fish, as well as the non-Antarctic Perciformes species Notolabrus celidotus (NC). Icefish have evolved a suite of physiological adaptations to account for their loss of haemoglobin (Kock 2005), following their diversification from the other Antarctic notothenioids, and we sought to determine whether $\mathrm{CH}$ had a different membrane lipid profile to the two closely related Antarctic fish species (PB and TB). Previous study indicates that erythrocyte membranes of icefish have fluidity consistent with those of TB, but with observed lipid differences (Palmerini et al. 2009). It is unknown whether the membrane lipid composition of other icefish tissues, especially liver, also differs from other notothenioids. Secondly, we investigated the acclimatory response of Antarctic fish to higher temperatures by examining 
97 whether thermal stress at $4{ }^{\circ} \mathrm{C}$ and $6{ }^{\circ} \mathrm{C}$ resulted in membrane restructuring in two Antarctic fish 98 species (PB and TB), as indicated by altered membrane saturation states and cholesterol content.

102

103

104

105

106

107

108

109

110

111

112

113

114

115

116

117

118

119

120

121

122

123

124

We hypothesised that membrane saturation, the major thermal adaptive mechanism, would occur only at reduced levels in Antarctic notothenioid fish as a response to elevated temperatures due their stenothermal nature, and thus make them vulnerable to the effects of AGW.

\section{Materials and Methods}

\section{Fish samples}

The fish species used in the study are described in Table 1, and details of the fish harvest and husbandry are provided in S1 (supporting information). The field study comprising thermal acclimation experiments were conducted in the laboratory facilities at Scott Base, Antarctica approved by Antarctica New Zealand (K058 - 2007/2008). The procedures of fish handling were approved by the Animal Ethics Committees at the University of Canterbury (AEC 2006/2R and 2008/11R). Liver tissue from Antarctic notothenioid and non-Antarctic fish species sampled from their normal habitat were taken for the establishment of normal lipid profiles. PB and TB and $\mathrm{CH}$ were compared with the non-Antarctic fish NC, a common native New Zealand Perciformes species (Ayling \& Cox 1982). NC is non-migratory and has a broad thermal range (eurythermal), experiencing daily and seasonal variations in temperature (Jones 1984). NC has been studied as a model temperate species in studies investigating mitochondrial functions under thermal stress (Iftikar \& Hickey, 2013; Iftikar et al. 2014; Iftikar et al. 2015). NC has also been compared with Antarctic species PB in a physiological study, to assess the association of anaerobic performance with cold habitat (Tukey \& Davison 2004). In this study, PB and TB samples comprised the preacclimation controls of the thermal acclimation experiment described, while sampling locations of $\mathrm{CH}$ and $\mathrm{NC}$ are provided in Table 1.

\section{Thermal acclimation experimental design}

Following the pre-acclimation period of 15 days, five randomly chosen individuals of each fish species were euthanised before the thermal acclimation experiment started and their tissues were harvested as an initial control prior to temperature treatment. The remaining fish of each species were randomly selected and placed in either static or flow-through tanks (limitations of the aquaria 
125 facilities meant some treatments were in static tanks) and kept in groups of no more than 10 fish 126 per tank. The capacity of each tank being 101 . There were three treatment temperatures, which 127 were $-1{ }^{\circ} \mathrm{C}$ control treatment, $4{ }^{\circ} \mathrm{C}$ and $6{ }^{\circ} \mathrm{C}$ acclimation temperature treatments respectively. The 128 control and $4{ }^{\circ} \mathrm{C}$ treatments comprised of three tanks, while the $6{ }^{\circ} \mathrm{C}$ acclimation temperature, 129 had only one tank. The initial temperature of all the tanks was $-1{ }^{\circ} \mathrm{C}$ at the time of fish transfer

130

131

132

133

134

135

136

137

138

139

140

141

142

143

144

145

146

147

(2)
and, for the acclimation temperature treatments, the water temperature was then gradually increased from $-1{ }^{\circ} \mathrm{C}$ to $4{ }^{\circ} \mathrm{C}$, or $6{ }^{\circ} \mathrm{C}$. The experimental temperature regime consisted of stepwise increases in temperature to the target temperature over a $24 \mathrm{~h}$ period (except in the case of the $6{ }^{\circ} \mathrm{C}$ treatment, in which case slower acclimation over three days was employed). The tanks were maintained at the treatment temperature $\pm 0.3{ }^{\circ} \mathrm{C}$ using two heat exchangers connected to a feeder tank that contained thermostatically-controlled water heater. Where possible, flow-through tanks were used, but by necessity, some of the heat treatments required the use of static tanks with oxygen bubblers. For static tanks, $25 \%$ of the tank capacity was replaced daily to avoid accumulation of waste products and decreases in oxygen concentration. A cohort of fish held at as close to environmental temperature as possible was used as a control treatment; in which case fish remained at $-1{ }^{\circ} \mathrm{C}$ for the duration of the experiment. Further, they were fed ad libitum twice weekly during the acclimation period. PB was acclimated for 28 days but TB species was only acclimated for 14 days primarily due to limitations in the Antarctic aquaria space and duration of the field season. A $24 \mathrm{~L}$ : 0D photoperiod was maintained to model the summer conditions in McMurdo Sound.

\section{Sampling of tissue and plasma samples}

Fish ( $\mathrm{n}=5)$ of each treatment, including controls) were euthanised, blood samples collected and tissues harvested at 1, 2, 3, 7, 14 and (in the case of PB only) 28 days post-acclimation, for $6^{\circ} \mathrm{C}$ thermal acclimation tissues were harvested after 7 days post acclimation for both the species PB and TB. Sampling procedures were performed at the Scott Base Wet Laboratory, with air temperature below $5^{\circ} \mathrm{C}$. Routine anaesthetic exposure via transfer to seawater containing MS-222 (ethyl m-amino benzoate methane-sulfonate) was performed. Fish were anaesthetised for five minutes in a $0.1 \mathrm{~g} / \mathrm{L}$ solution of MS222 dissolved in sea water. Details of the individual fish were then recorded such as fish morphology, weight, length, sex, maturity stage, blood volume, parasite 
155 burden and tissues collected. Blood was collected from the caudal vein with a needled syringe (22 156 guage) and the fish was euthanised by severing the spinal cord. Fish were dissected using standard 157 dissection procedures under sterile conditions and tissue samples were transferred into labelled 158 vials and immediately frozen in liquid nitrogen. Tissues (liver, brain, heart, kidney, white muscle, 159 red muscle, subcutaneous fat and adipose tissue) were rapidly removed, snap frozen in liquid 160 nitrogen and stored at $-80^{\circ} \mathrm{C}$ for later biochemical and genetic analyses.

\section{Phospholipid fatty acid analysis}

\section{Lipid extraction}

163 The lipid extraction method followed that of Folch et al. (1957) but was modified as follows. Total

164 lipids were extracted from $0.2 \mathrm{~g}$ frozen liver tissue. Samples were ground under liquid nitrogen 165 and suspended in $6 \mathrm{ml}$ of dichloromethane/methanol 2:1, $0.01 \%$ butylated hydroxytoluene (BHT). 166 After sonication (W-225 from Watson Victor) for 5 minutes, $2 \mathrm{ml}$ of $0.88 \%$ potassium chloride was added. The samples were vortexed for two minutes and centrifuged at $1000 \mathrm{~g}$ for 5 minutes. The aqueous layer was re-extracted with $2 \mathrm{ml}$ of dichloromethane/methanol 2:1, $0.01 \%$ BHT and the two organic layers combined and dried under nitrogen. Dried samples were then stored at $4{ }^{\circ} \mathrm{C}$ until fractionation.

\section{Lipid fractionation}

172 The lipid fractionation method followed that of Zelles (1997), but was modified as follows. 173 Phospholipids were separated by re-suspending the total lipid extracts in chloroform and loading 174 on to a solid phase extraction column (Biotage isolute SI $500 \mathrm{mg} 6 \mathrm{ml} \mathrm{SPE}$ ). The sample was 175 allowed to stand for 2 minutes in the column and the lipids sequentially eluted with $5 \mathrm{ml}$ of 176 chloroform for elution of neutral lipids, $5 \mathrm{ml}$ of acetone for glycolipids and $5 \mathrm{ml}$ of methanol for 177 phospholipids. The phospholipid fraction was dried with nitrogen then stored at $4{ }^{\circ} \mathrm{C}$ before 178 proceeding with methylation.

\section{Methylation}

The tubes containing the evaporated samples were brought to room temperature and $1 \mathrm{ml}$ of tetrahydrofuran: methanol $(1: 1 \mathrm{v} / \mathrm{v})$ was added, then vortexed for 30 seconds. $1 \mathrm{ml}$ of $0.2 \mathrm{M}$ potassium hydroxide was added followed by 30 seconds vortex and incubation at $37{ }^{\circ} \mathrm{C}$ for 15 
183 minutes. After incubation, $2 \mathrm{ml}$ of hexane: chloroform (4:1) plus $0.3 \mathrm{ml}$ of $1 \mathrm{M}$ acetic acid and 2 $184 \mathrm{ml}$ of deionised water were added and vortexed for 1 minute followed by centrifugation at $1000 \mathrm{~g}$ 185 for 5 minutes. The top organic layer was transferred to a holding tube and $2 \mathrm{ml}$ of hexane: 186 chloroform (4:1) was added to the lower aqueous layer and vortexed for 1 minute followed by 187 centrifugation at $1000 \mathrm{~g}$ for 5 minutes. The top organic layer was transferred to the holding tube 188 containing the first organic fraction. The organic layer was evaporated under $\mathrm{N}_{2}$ in a water bath at $37^{\circ} \mathrm{C}$. Hexane $(50 \mu \mathrm{l})$ was added to the evaporated organic layer and this was then transferred to a $150 \mu \mathrm{l}$ insert with a poly spring held in an amber vial for GC analysis.

191

192

194

195

196

197

198

199

200

201

202

203

204

205

206

207

\section{Gas chromatographic separation}

Fatty acid methyl esters were analysed on a Shimadzu GC-2010 Gas Chromatograph (Shimadzu, Tokyo, Japan) fitted with a silica capillary column (Varian CP7420, 100m, ID 0.25mm, film thickness $0.25 \mu \mathrm{m}$, Serial \# 6005241) and helium flow $0.96 \mathrm{ml} / \mathrm{minute}$. The split ratio was 15 to 1 and the injector temperature was $250^{\circ} \mathrm{C}$. The initial column temperature was $45^{\circ} \mathrm{C}$ for 4 minutes, then ramped at $13{ }^{\circ} \mathrm{C} /$ minute to $175^{\circ} \mathrm{C}$ held for 27 minutes before another ramp of $4{ }^{\circ} \mathrm{C} /$ minute to $215^{\circ} \mathrm{C}$. This temperature was held for 35 minutes before a final ramp $25^{\circ} \mathrm{C} /$ minute to $245^{\circ} \mathrm{C}$ for 5 minutes. All GLC conditions were based on adapting the initial conditions indicated by Lee and Tweed (2008). A flame ionisation detector was used at $310^{\circ} \mathrm{C}$ and fatty acids were identified by comparison of retention times to standards (GLC 463, NuChek). Known fatty acids are reported as a percentage of total fatty acids and fatty acids less than $1 \%$ were not reported.

\section{Membrane cholesterol analysis}

Cholesterol was extracted with dichloromethane: methanol from $50 \mathrm{mg}$ of liver tissue resuspended in $1 \mathrm{ml}$ of 2-methoxymethane, then stored at $-80^{\circ} \mathrm{C}$ (Gonzalez et al. 2013). The free cholesterol was measured using the cholesterol fluorometric assay 10007640 following the manufacturer's instructions (https://www.caymanchem.com/pdfs/, Kit item number 10007640) and read on a Fluorostar omega microplate reader (BMG Labtech). 
208 Plasma osmolality determination

209 Collection and storage of plasma samples

210 Blood samples from the experimental Antarctic fish (TB, PB) were collected at Scott Base Wet 211 Laboratory. The temperature of the Wet Laboratory was constantly below $5{ }^{\circ} \mathrm{C}$. The experimental 212 fish were anaesthetised for five minutes by administration of $0.1 \mathrm{~g} \mathrm{~L}-1$ solution of MS222 (ethyl $213 \mathrm{~m}$-amino benzoate methane sulphonate) dissolved in sea water. Blood samples were immediately 214 drawn by cardiac puncture with a 25 gauge needle. Blood volume of 0.5 to $1.0 \mathrm{ml}$ was collected 215 into a tube containing anti-coagulant. The collected blood was centrifuged at $3000 \mathrm{~g}$ for two 216 minutes for the plasma separation. The resultant blood plasma was collected and snap frozen in

217 liquid nitrogen and transported to New Zealand in an insulated container containing dry ice and 218 then stored at $-80{ }^{\circ} \mathrm{C}$. Plasma from fish samples from both the species acclimated to $4{ }^{\circ} \mathrm{C}$ and the 219 control temperature of $0{ }^{\circ} \mathrm{C}$, and collected at all the time-points, were taken for osmolality analysis. 220 The plasma samples were thawed to room temperature and $10 \mu 1$ plasma aliquots were taken for 221 osmolality determination. Osmolality was measured using a Wescor $5520 \mathrm{C}$ vapour pressure osmometer, which was calibrated with standard solutions before the measurements.

\section{Calculations and statistics}

224 All statistical analysis was performed using Minitab v17 software. Comparison of lipid profiles of the different species was performed using principal component analysis (PCA) based on a correlation matrix. The raw data consisted of a matrix of the percent contribution of each phospholipid fatty acid in each sample. The data were not transformed prior to analysis. One way ANOVA followed by a Holm-Sidak post hoc test was performed to compare individual fatty acids among the four fish species.

Desaturase index (DSI) for $\Delta 9$-desaturase/Stearoyl-CoA desaturase (SCD) was calculated as the ratio of product to precursor of the individual fatty acids using the formula: $\mathrm{C} 16: 1 \mathrm{n} 7 / \mathrm{C} 16: 0$ and C18:1n9/C18:0)(Cormier et al. 2014). Two particular unsaturated fatty acids (C16:1n7 and C18:1n9) were used for DSI, as the ratio of $(\mathrm{C} 16: 1 \mathrm{n} 7 / \mathrm{C} 16: 0)$ and $(\mathrm{C} 18: 1 \mathrm{n} 9 / \mathrm{C} 18: 0)$ has been shown to correlate with Stearoyl-CoA desaturase activity, degree of desaturation and membrane fluidity in a previous study (Hsieh \& Kuo 2005). 
236 Two-way ANOVA was used to assess the effects of temperature (control $0{ }^{\circ} \mathrm{C}$ and acclimated 4

$237{ }^{\circ} \mathrm{C}$ ), acclimation time (days) and the interaction between temperature and time on plasma

238 osmolality. A Holm-Sidak post hoc test was subsequently used to determine which treatments

239 differed significantly. Remaining data analysis in the $4{ }^{\circ} \mathrm{C}$ and $6{ }^{\circ} \mathrm{C}$ thermal acclimation trials was

240 performed using an unpaired Student $t$ test.

241 To assess whether the data met the assumptions of ANOVA, an approximation of residuals to a normal distribution was established by visual inspection, and homogeneity of variances was confirmed using Bartlett's test. For one variable, the PB osmolality, variances were found to be significantly different among the treatment groups, even after transformation of the data (square root; log) was attempted. ANOVA is frequently considered robust against the assumption of equal variances, especially when sample sizes are approximately equal (Ananda \& Weerahandi, 1997). Thus, we proceeded with the ANOVA in this case, but concede that the results should be treated with caution due to the reduced power of the test under these conditions

\section{Results and Discussion}

\section{Novelty of the study and key results}

251

252

253

254

255

256

257

258

259

260

261

262

263

This is the first study to show that higher temperature acclimation can induce a homeoviscous response in an Antarctic fish species; the response was dominated by changes in membrane unsaturation while membrane cholesterol remain unchanged. Our results also reveal that the presence of a homeoviscous response can vary depending on the Antarctic fish species. Thermal acclimation to $4{ }^{\circ} \mathrm{C}$ did not induce the HVA response in either of the Antarctic speciesTB or PB. However, an HVA response was induced in one of the Antarctic fish species, TB, when it was acclimated to a warming temperature of $6{ }^{\circ} \mathrm{C}$. In addition, apart from palmitic acid which had similar levels in icefish and the non-Antarctic fish species, the membrane fatty acid composition of Antarctic fish species was found to differ from that of a non-Antarctic fish species at their respective typical environmental temperatures.

\section{Distinct phospholipid fatty acid composition of Antarctic species}

The first two principal components (PCs) of the PCA of the phospholipid profiles explained 76.4 $\%$ of the variance in the data matrix. The PCA clearly separated the phospholipid profiles of the 
264 three Antarctic fish species (PB, TB and $\mathrm{CH}$ ) from the samples obtained from the non-Antarctic 265 species (NC) along PC1 (Figure 1). The non-Antarctic fish NC was associated with high 266 proportions of saturated fatty acids (C18:0) and the PUFA (C20:4n6), while the Antarctic species 267 (all three) were associated with high MUFAs (C16:1n7, C18:1n7, C20:1n9 and an unidentified 268 MUFA, C20:1), and PUFA (C20:5n3) (Figure 1; Table 2). Within the Antarctic species, the 269 phospholipid profiles of closely-related species TB and PB were separated from those of the more 270 distantly-related $\mathrm{CH}$ along PC2 (Figure 1). CH was associated with relatively high proportions of 271 the SFA C16:0 and the MUFAs C18:1n9 and C20:1n9, whereas PB and TB had higher levels of 272 the MUFA C16:1n7 and the unidentified MUFA (C20:1).

Generally the eurythermal NC had a significantly higher total SFA and lower total MUFA when compared to the Antarctic fish species, but this distinction was not specific for the total PUFA 275 (Table 2). Our results suggest that the Antarctic fish species membrane fatty acid profiles are relatively consistent and distinct when compared to the eurythermal species (NC)(Figure 1; Table 2). Stenothermal fish species such as Antarctic fish exist in constant cold and have a narrow thermal adaptable range, and have been reported to have higher percentages of unsaturated fatty acids than temperate fish or eurythermal fish (Logue et al. 2000). Similarly liver microsomes of Antarctic fish Disostichus mawsomi had higher percentages of MUFA when compared to the temperate fish such as trout and carp (Römisch et al. 2003). In our study it's the overall MUFA and some specific PUFA that are higher in Antarctic than the non-Antarctic fish species suggestive of a central role of MUFA than PUFA in cold adaptation for Antarctic fish, and this phenomenon is considered as part of adaptive homeoviscous response in the fish acquired over their evolutionary history (Cossins 1977; Hsieh \& Kuo 2005; Trueman et al. 2000; Williams \& Hazel 1995). A key question of this study was to determine whether the recently diversified icefish $(\mathrm{CH})$ differ in their membrane lipids when compared to the other Antarctic fish species. This study shows that proportions of saturated fatty acids (SFAs), primarily palmitic acid (C16:0), were similar in the Antarctic species $\mathrm{CH}$ and the non-Antarctic species $\mathrm{NC}$; both of these species had significantly higher levels of C16:0 compared to the Antarctic species TB and PB (Table 2). Higher proportions of $\mathrm{C16:0}$ in the membranes of the icefish liver could be one feature acquired after diversification from the other Antarctic species. A previous study on the erythrocyte membrane lipids of $\mathrm{CH}$ showed higher levels of unsaturated longer chain fatty acids such as C:20-C:22, while shorter chain fatty acids such as $\mathrm{C}: 16$ and $\mathrm{C}: 18$ became unsaturated in TB, with both species 
295 having consistent membrane fluidity(Palmerini et al. 2009). The icefish species could thus have

296 evolved specific adaptations in liver membrane lipids, such as higher C16:0 levels in liver 297 membranes, as shown in the present study, and unsaturation of longer chain fatty acids in 298 erythrocyte cell membranes (Palmerini et al. 2009).

299 Palmitic acid was significantly lower for the two closely related Antarctic species (TB and PB) 300 than the New Zealand species NC, and the other Antarctic species CH (Table 2), and also formed 301 the major fraction of the total saturated fatty acids in the Antarctic fish species. Stearic acid (18:0) 302 was significantly lower in all three Antarctic species and formed the minor fraction. Palmitic acid 303 has a role in cold adaptation of membranes (Farkas et al. 1994) and may be the reason for the 304 predominance of palmitic acid among the saturated fatty acids in our study (Table 2). These results 305 align with a study comparing the phospholipid compositions of muscle tissue in 15 marine species 306 from the southeast Brazilian coast and two species from East Antarctica, where palmitic acid 307 comprised 54-63\% of the total SFA content (Visentainer et al. 2007); and another study examining the total fatty acid content for all organs in two Antarctic species, Notothenia coriceps and Notothenia rossii, where palmitic acid represented $16-30 \%$ of the total FA content for all organs (Magalhaes et al. 2010). Apart from high palmitic acid in Antarctic fish, increases in palmitic acid due to cold acclimation was observed in a study comparing two confamiliar species from different thermal habitats in the muscle of Antarctic eelpout, Pachycara brachycephalum in comparison to the temperate eelpout Zoarces (Brodte et al. 2008).

\section{Components of MUFA enhance membrane fluidity}

315 All three Antarctic fish species were associated with high levels of monounsaturated fatty acids 316 (MUFA) associated with membrane fluidity, such as palmitoleic acid (C16:1n7), cis-vaccenic acid 317 (C18:1n7), eicosenoate (C20:1n9) and total MUFA (Figure 1; Table 2). Other studies have reported high cis-vaccenic acid in membranes of the Antarctic fish Pleuragramma antarcticum 319 (Mayzaud et al. 2011), high latitude fish of the sub-Arctic (Murzina et al. 2013), and Caenorhabditis elegans worms exposed to cold (Murray et al. 2007). Cis-vaccenic acid has been shown to enhance glucose transport in adipocytes (Pilch et al. 1980) and serotonin transport in endothelial cells (Block \& Edwards 1987). The conformation of unsaturated cis-vaccenic acid presents a possible structural advantage and has a potential role in maintaining membrane fluidity, which may be the reason for its selective incorporation in the membranes of Antarctic fish. Lower 
325 growth temperature has also been shown to increase the amount of cis-vaccenic acid in E.coli and

326 decrease the amount of palmitic acid incorporated in their membranes (Marr \& Ingraham 1962).

327

328

329

330

331

332

333

334

335

336

337

338

339

340

341

342

343

344

345

346

347

348

349

350

351

352

353

354

\section{EPA could offer additional roles other than membrane fluidity}

Antarctic fish species had significantly lower levels of arachidonic acid (ARA, C20:4n6) and higher levels of eicosapentaenoic acid (EPA, C20:5n3) than non-Antarctic species (Figure 1; Table 2). Levels of docosahexaenoic acid (DHA, C22:6n3) were not significantly different between Antarctic and non-Antarctic species (Table 2). Higher EPA proportions in the Antarctic fish species included in our study is in alignment with high EPA levels observed in muscle phospholipids of Antarctic fish from the Weddell and Lazarev Seas (Hagen et al. 2000), in Antarctic silverfish, Pleuragramma antarcticum (Mayzaud et al. 2011), incold acclimated fresh water alewives (Alosa pseudoharengus) (Snyder et al. 2012) and in cold acclimated Caenorhabditis elegans (Murray et al. 2007). Higher EPA in Antarctic species, and high EPA induced by cold acclimation in other species, suggest that EPA may play a role associated with cold tolerance, such as anti-inflammation or membrane stabilization. It has been suggested that DHA may possess a structural advantage over EPA in contributing to membrane fluidity due to the expanded molecular conformation of DHA (Hashimoto et al. 2006). We did not see an increase in DHA and perhaps MUFA perform this role in Antarctic species. EPA, but not DHA, has been shown to be a potent anti-inflammatory agent, whereas ARA is highly pro-inflammatory (Sears \& Ricordi 2011; Seki et al. 2009). Hyper cholesteraemic rats, in whose membrane fluidity is reduced, have been shown todisplay increased membrane fluidity in their platelets when fed DHA but not when fed EPA (Hashimoto et al. 2006). EPA may help in stabilization of hyper fluid membranes, as indicated by a study of the bacterium Shewanella violacea (Usui et al. 2012). EPA is one of the major (n-3) PUFAs present in the membranes of the Antarctic fish and contrary to other studies we do not observe correlation of DHA with membrane unsaturation, suggestive of modulation of particular fatty acids in HVA response. How these fatty acids (EPA, DHA and MUFA) contribute to fluidity and any other roles need further investigation in a larger range of fish species.

\section{Lack of distinction of membrane cholesterol between Antarctic fish and a New Zealand fish species.}

Membrane cholesterol was higher in the non-Antarctic New Zealand species NC than the Antarctic species $\mathrm{PB}$, but not different to $\mathrm{CH}$ and $\mathrm{TB}$ (Figure2). In general, ectotherms adapted to lower 
355 temperature have shown to have reduced cholesterol levels primarily for maintenance of fluid state 356 of membranes (Crockett 1998). Contrary to the trend of a direct relationship with membrane 357 cholesterol and habitat temperature, a higher percentage of cholesterol in muscle was observed in 358 the higher Arctic fish species Leptoclinus maculatus in comparison to the related sub-Arctic 359 species Lumpenus fabricii (Murzina et al. 2013). Currently there is limited data on the membrane 360 cholesterol of Antarctic fish species. Our study showed cholesterol content varies with species, 361 rather than the habitat temperature, a similar finding to those of (Palmerini et al. 2009) where 362 cholesterol in erythrocyte ghost membranes was highest in $\mathrm{CH}$, followed by the non-Antarctic 363 species Anguilla anguilla, and then lower in other Antarctic and non-Antarctic species. Thus, 364 membrane cholesterol from further Antarctic species and from different tissues needs to be 365 determined to establish its role in homeoviscous adaptation.

\section{Lack of homeoviscous response in Antarctic species at $4{ }^{\circ} \mathrm{C}$ thermal acclimation}

367

368

369

370

371

372

373

374

375

376

377

378

379

380

381

382

Thermal acclimation at $4{ }^{\circ} \mathrm{C}$ did not induce the major common cellular homeoviscous response in either the pelagic species (PB) or the benthic species (TB) after 28 or 14 days, respectively (Table $3)$. There was no change in the desaturase index $(\mathrm{C} 16: 1 \mathrm{n} 7 / \mathrm{C} 16: 0)$ and $(\mathrm{C} 18: 1 \mathrm{n} 9 / \mathrm{C} 18: 0)$ in either species (Table 3). In TB, thermal acclimation changed the PUFA profile with a decrease in EPA (C20:5n6) levels and an increase in the amount of DHA (C22:6n6) (Table 3). As explained above, EPA levels may have a specific function in the extreme cold, perhaps in stabilizing membranes (Usui et al. 2012), or a protective role by reducing inflammation (Sears \& Ricordi 2011; Seki et al. 2009). The present findings of unchanged saturation states for PB and TB align with previous thermal acclimation experiments at $4^{\circ} \mathrm{C}$ in the benthic Antarctic notothenioid species T. bernacchii and Trematomus newnesi, where membrane unsaturation states were unchanged and there was no sign of an HVA response in the membranes of gills, kidneys, liver and muscle (Gonzalez-Cabrera et al. 1995). Similarly, mitochondrial membrane saturation states were also unchanged upon thermal acclimation and acidification, in the Antarctic species Notothenia rossii acclimated at 7 ${ }^{\circ} \mathrm{C}$ and the sub-Antarctic species Lepidonotothen squamifrons acclimated at $9{ }^{\circ} \mathrm{C}$ (Strobel et al. 2013). Our findings have extended these observations to a cryopelagic species (PB), as well as confirming the lack of change in membrane saturation state in the benthic species TB. 
383 Thermal acclimation has no effect on membrane cholesterol in the Antarctic species

384 Cholesterol is known to counter the effects of increased temperature on membrane lipids and an 385 increase in cholesterol is often observed at high temperatures (Crockett 1998). The structure of cholesterol mimics phospholipid structure and intercalates in the phospholipid membrane bilayer, resulting in an increase in membrane order and a reduction in membrane fluidity (Crockett 1998). However, the membrane cholesterol in PB as well as TB was unaffected by thermal acclimation (Figure 3; $\mathrm{P}>0.05$ ). This may be a tissue-specific effect as increased temperature resulted in a significant decline of cholesterol in the gill membranes of goldfish, but had no effect on the brain and liver cholesterol concentration (Gonzalez et al. 2013).

392

393

394

395

396

397

398

399

400

401

402

403

404

405

406

407

408

409

410

411

\section{Thermal acclimation results in a decline in plasma osmolality in both Antarctic species}

Plasma osmolality gives an indication of the functioning of membranes. An inverse relationship exists between serum osmolality and water temperature. In an analysis of 11 teleost species, the serum concentration of Antarctic species was higher than the temperate species (Dobbs \& DeVries 1975). Fish inhabiting cold waters have high serum inorganic ion concentrations and these inorganic ions have been shown to have protective roles in freezing avoidance by decreasing the melting point (O'Grady \& DeVries 1982). The plasma osmolality change over the 28 days of thermal acclimation at $4{ }^{\circ} \mathrm{C}$ in $\mathrm{PB}$ is presented in Figure 4. Overall, irrespective of days of acclimation the osmolality at $4{ }^{\circ} \mathrm{C}$ was significantly lower in $\mathrm{PB}(\mathrm{P}<0.01)$, while a numerical but non-significantly decline with temperature increase was observed for TB. The osmolality fell in both species after Day 3 of thermal acclimation and the reduction was significant at Day 7 $(\mathrm{P}<0.01)$. Plasma osmolality in $\mathrm{PB}$ at $0{ }^{\circ} \mathrm{C}$ over the 28 days of acclimation remained unchanged $(\mathrm{P}>0.05)$. The plasma osmolality showed a decreasing trend over the 14 day acclimation to $4^{\circ} \mathrm{C}$ in TB, but this was not statistically significant (Figure 4). In our study, thermal acclimation caused a decline in serum osmolality for PB. Other studies have also shown reduced osmolality upon thermal acclimation (Gonzalez-Cabrera et al. 1995; Guynn et al. 2002; Hudson et al. 2008; Lowe \& Davison 2005) which in some cases has been attributed to increased $\mathrm{Na}+/ \mathrm{K}+-\mathrm{ATPase}$ activity (Guynn et al. 2002). The ability of these fish to control osmolality indicated that membranes were still functioning at $4{ }^{\circ} \mathrm{C}$. 
412 Thermal acclimation at $6^{\circ} \mathrm{C}$ results in an $\mathrm{HVA}$ response in $\mathrm{T}$. bernacchii, but not in 413 the pelagic species $P$. borchgrevinki

414 One of the key HVA responses is the change in the saturation states of membrane phospholipids

415 (Hazel 1995). TB exhibited an HVA response at $6{ }^{\circ} \mathrm{C}$ (Figure 5), as shown by the increase in 416 overall SFAs due to an increase in stearic acid, along with a decline in MUFA component 417 eicosenoic acid (C20:1n9), total MUFAs and the PUFA component EPA (C20:5n3), while a 418 significant increase in DHA (C22:6n3) was observed. Saturated fatty acids reduce membrane 419 fluidity and offset the effects of increased temperature (Hazel 1995). Previous studies of non420 Antarctic fish species have shown that warm acclimation resulted in increased SFA and a decline 421 in PUFAs viz., EPA, DHA and ARA in brain phospholipids of Dicentrarchus labrax (Skalli et al. 422 2006), which has also been seen in fresh water alewives (Alosa pseudoharengus) (Snyder et al. 423 2012). In yellow perch (Perca flavescens) warm acclimation resulted in decline of MUFA and 424 PUFA in muscle phospholipids (Fadhlaoui \& Couture 2016). Although, the mechanism of HVA 425 response upon warm acclimation is primarily dominated by a decrease in unsaturation, within this 426 we observed an increase in DHA upon warm acclimation in TB at $4{ }^{\circ} \mathrm{C}$ (Table 3) and at $6{ }^{\circ} \mathrm{C}$ 427 (Figure 6), suggesting that particular fatty acids are modulated by temperature which could differ 428 with tissue type and individual fish species. Tissue specific responses were also observed when 429 warm acclimation induced an increase in DHA and palmitic acid in goldfish liver, but not in brain, 430 gill and muscle membrane lipids (Gonzalez et al. 2013) and also the role of DHA have shown to 431 vary among the eurythermal and stenothermal fish (Brodte et al. 2008). In eurythermal fish DHA 432 is involved in cold acclimation as seen by increase in DHA of mitochondrial phospholipids with 433 cold acclimation in rainbow trout (Guderley et al. 1997), similarly cold acclimation in carp resulted in DHA increase in liver phospholipids (Farkas et al. 1980). While in this study, increase in DHA in stenothermal Antarctic fish TB with temperature increase suggest, DHA does not participate in cold adaptation. Similarly in the Antarctic fish Pachychara bracycephalum, high DHA correlated with temperature of highest growth in the muscle and liver tissue suggestive of a role in growth rather than with cold adaptation (Brodte et al. 2008). Thus our study supports the dual role of DHA depending on thermal environment of fishes.

440 In PB we found that $6{ }^{\circ} \mathrm{C}$ did not induce a significant HVA response (Figure 6 , although there was

441 a decline in the MUFA component eicosenoic acid. Warm acclimation inboth TB and PB caused 442 a significant reduction of eicosenoic acid (Figure 5 and 6). At their normal environmental 
443 temperature, these fish are found to have high proportions of eicosenoic acid in their membranes,

444 as shown in analysis of the general phospholipid profile (Figure 1), when compared to the New

445 Zealand species, in which it was not detected. A similar role of eicosenoic acid in HVA response

446 was observed in warm acclimated goldfish, with a decrease in the percent eicosenoic acid of brain

447 and muscle phospholipids (Gonzalez et al. 2013). Apart from the reduction in eicoseonic acid, a

448 major HVA response was not seen in PB. Other tissues may need to be analysed to confirm the

449 apparent lack of a significant HVA response in PB. For example, the warm acclimation of

450 Dicentrarchus labrax resulted in an HVA response in the brain, rather than the liver (Skalli et al.

451 2006). In another study, warm acclimation of the Antarctic species Notothenia rossii at $7{ }^{\circ} \mathrm{C}$ and

452 Lepidonotothen squamifrons at $9{ }^{\circ} \mathrm{C}$ did not result in an HVA response in mitochondrial

453 membranes (Strobel et al. 2013). PBhas a higher degree of thermal plasticity (Franklin et al. 2007)

454 and higher upper lethal temperature compared with TB (Somero \& DeVries 1967). Thus,

455 temperatures greater than $6^{\circ} \mathrm{C}$ may be required to induce an HVA response in PB.

456 Desaturase index correlates with membrane saturation state

457 In the present study the desaturase index (DSI) (C16:1n7/C16:0) and (C18:1n9/C18:0) were shown

458 to correlate with the saturation states of the membrane and DSI has been used as a surrogate for

459 the measurement of stearoyl-CoA desaturase (SCD) enzyme activity in membrane remodelling in

460 response to temperature (Fadhlaoui \& Couture 2016). The enzyme SCD plays a key role in

461 unsaturation of SFA by catalysing the synthesis of MUFA, primarily by the introduction of the

462 first double bond between the C9 and C10 position of the fatty acid which results in increased

463 membrane disorder and enhanced fluidity (Paton \& Ntambi 2009). The Antarctic species had a

464 high desaturase index $(\mathrm{C} 16: 1 \mathrm{n} 7 / \mathrm{C} 16: 0)$ compared to the non-Antarctic species, whereas this trend

465 is not specific for the DSI (C18:1n9/C18:0) (Figure 7). High DSI (C16:1n7/C16:0) in the Antarctic

466 fish species could be attributed to an increase in the MUFA palmitoleic acid C16:1n7 reflecting

467 higher desaturation of palmitic acid by SCD. Furthermore, in this study there was significant

468 decline in DSI (C16:1n7/C16:0) upon thermal acclimation at $6^{\circ} \mathrm{C}$ in $T$. bernacchii (Figure 8). A

469 positive correlation does exist with the desaturase index and membrane saturation states, as

470 previously established in two fish species, milk fish and the grass carp when subjected to cold

471 acclimation from $25^{\circ} \mathrm{C}$ to $15^{\circ} \mathrm{C}$ over 21 days (Hsieh \& Kuo 2005). Similarly higher desaturase

472 index for SCD-18 (stearate desaturase) was observed in yellow perch (Perca flavescens)

473 acclimated at $9{ }^{\circ} \mathrm{C}$ than at $28^{\circ} \mathrm{C}$ (Fadhlaoui \& Couture 2016). Further our study supports this 
474 change specifically for the palmitate DSI $(\mathrm{C} 16: \ln 7 / \mathrm{C} 16: 0)$ rather than for the stearate DSI

475 (C18:1n9/C18:0) (Figure 7 and 8). Hence the Antarctic species could display specificity for the 476 palmitate desaturase activity for the HVA response. However, desaturase index provides limited 477 information as it does not convey the complete picture of the lipid saturation, and data on the 478 storage lipid dynamics is needed to establish the complete correlation of DSI. Future studies are 479 needed to assess the compartmentalization of DSI for the membrane lipid saturation, fatty acid 480 synthesis, and chain elongation. A study on the compartmentalization of SCD1 activity in HepG2 481 cell lines have provided additional information on lipid pathways by determination of desaturation 482 index in HepG2 cell lines using labelled stearate or palmitate (Yee et al. 2008).

\section{Conclusions and perspectives}

485

486

487

488

489

490

491

492

493

494

495

496

497

498

499

500

501

502

503

This study has established a consistent membrane lipid profile across three notothenioid Antarctic species, in contrast to a varying membrane lipid composition between Antarctic species and a nonAntarctic New Zealand species. The Antarctic fish exhibit an evolutionary HVA response, as reflected by high levels of unsaturated fatty acids and selective dominance of cis-vaccenic acid and EPA in their membranes. This calls for further analysis of a wide range of fish species from different thermal habitats to decipher the specific roles of cis-vaccenic acid and EPA in cold adaptation. Previously undetermined is whether Antarctic fish can protect their membranes by exhibiting the acclimatory HVA response, which may make them less vulnerable to the effects of AGW. Our findings suggest that at $4{ }^{\circ} \mathrm{C}$ neither of the closely related Antarctic species exhibited any significant HVA response either with phospholipid unsaturation or with membrane cholesterol, but membrane-associated functions such as osmoregulation remain uncompromised. Furthermore, acclimatory HVA response of membrane unsaturation was detected at $6{ }^{\circ} \mathrm{C}$ in the liver of the benthic species TB while this response was lacking in liver membranes of the cryopelagic species PB. In the present study HVA response was dominated by phospholipid unsaturation with no change in membrane cholesterol and the potential role of cholesterol in HVA response in Antarctic fish still remain unclear. Future studies especially at higher temperature acclimation as well as in other tissues are needed to determine the role of membrane cholesterol to HVA response in Antarctic fish. In conclusion it appears that some Antarctic fish species can exhibit a limited HVA response to warming temperatures after a given acclimation period. 
504 However, this study has reinforced the need for further experimental work involving more species, 505 over a wider range of acclimation temperatures and assaying multiple tissue types in order to 506 ascertain the generality or specificity of acclimatory HVA responses in Antarctic fish.

Acknowledgements:

509 We thank Dr Adrian Paterson for input to manuscript preparation.

510

511

Data Availability

512 Raw data has been supplied as a supplementary file

513 Supplemental Information

514 Supporting information S1 Fish harvest and husbandry

\section{References}

516

517

518

519

520

521

522

523

524

525

526

527

528

529

530

531

532

533

534

535

536

537
Ananda MMA, and Weerahandi S. 1997. Two-way ANOVA with unequal cell frequencies and unequal variances. Statistica Sinica 7: 631-646.

Aronson RB, Thatje S, McClintock JB, and Hughes KA. 2011. Anthropogenic impacts on marine ecosystems in Antarctica. Annals of the New York Academy of Sciences 1223:82-107.

Ayling T, and Cox GJ. 1982. Collins Guide to the Sea Fishes of New Zealand. Auckland William Collins Publishers

Block ER, and Edwards D. 1987. Effect of plasma membrane fluidity on serotonin transport by endothelial cells. American Journal of Physiology - Cell Physiology 253:C672-C678.

Brodte E, Graeve M, Jacob U, Knust R, and Pörtner H-O. 2008. Temperature-dependent lipid levels and components in polar and temperate eelpout (Zoarcidae). Fish Physiology and Biochemistry 34:261-274.

Cormier H, Rudkowska I, Lemieux S, Couture P, Julien P, and Vohl M-C. 2014. Effects of FADS and ELOVL polymorphisms on indexes of desaturase and elongase activities: results from a pre-post fish oil supplementation. Genes \& Nutrition 9:437.

Cossins AR. 1977. Adaptation of biological membranes to temperature. The effect of temperature acclimation of goldfish upon the viscosity of synaptosomal membranes. Biochimica et biophysica acta 470:395-411.

Crockett EL. 1998. Cholesterol Function in Plasma Membranes from Ectotherms: Membrane-Specific Roles in Adaptation to Temperature. American Zoologist 38:291-304.

Dobbs GH, and DeVries AL. 1975. Renal function in Antarctic teleost fishes: Serum and urine composition. Marine Biology 29:59-70. 
538

539

540

541

542

543

544

545

546

547

548

549

550

551

552

553

554

555

556

557

558

559

560

561

562

563

564

565

566

567

568

569

570

571

572

573

574

575

576

577

578

579

580

581

582

583

584

585

586

587

588

Fadhlaoui M, and Couture P. 2016. Combined effects of temperature and metal exposure on the fatty acid composition of cell membranes, antioxidant enzyme activities and lipid peroxidation in yellow perch (Perca flavescens). Aquatic Toxicology 180:45-55.

Farkas T, Csengeri I, Majoros F, and Oláh J. 1980. Metabolism of fatty acids in fish: III. Combined effect of environmental temperature and diet on formation and deposition of fatty acids in the carp, Cyprinus carpio Linnaeus 1758. Aquaculture 20:29-40.

Farkas T, Dey I, Buda C, and Halver JE. 1994. Role of phospholipid molecular species in maintaining lipid membrane structure in response to temperature. Biophysical Chemistry 50:147-155.

Folch J, Lees M, and Sloane Stanley GH. 1957. A simple method for the isolation and purification of total lipides from animal tissues. J Biol Chem 226:497-509.

Franklin CE, Davison W, and Seebacher F. 2007. Antarctic fish can compensate for rising temperatures: thermal acclimation of cardiac performance in Pagothenia borchgrevinki. The Journal of Experimental Biology 210:3068-3074.

Gonzalez-Cabrera PJ, Dowd F, Pedibhotla VK, Rosario R, Stanley-Samuelson D, and Petzel D. 1995. Enhanced hypo-osmoregulation induced by warm-acclimation in antarctic fish is mediated by increased gill and kidney Na+/K(+)-ATPase activities. J Exp Biol 198:2279-2291.

Gonzalez A, Odjélé A, and Weber J-M. 2013. PCB-153 and temperature cause restructuring of goldfish membranes: Homeoviscous response to a chemical fluidiser. Aquatic Toxicology 144-145:11-18.

Guderley H, Pierre JS, Couture P, and Hulbert AJ. 1997. Plasticity of the properties of mitochondria from rainbow trout red muscle with seasonal acclimatization. Fish Physiology and Biochemistry 16:531-541.

Guynn S, Dowd F, and Petzel D. 2002. Characterization of gill Na/K-ATPase activity and ouabain binding in Antarctic and New Zealand nototheniid fishes. Comparative Biochemistry and Physiology Part A: Molecular \& Integrative Physiology 131:363-374.

Hagen W, Kattner G, and Friedrich C. 2000. The lipid compositions of high-Antarctic notothenioid fish species with different life strategies. Polar Biology 23:785-791.

Hashimoto M, Hossain S, and Shido O. 2006. Docosahexaenoic acid but not eicosapentaenoic acid withstands dietary cholesterol-induced decreases in platelet membrane fluidity. Molecular and Cellular Biochemistry 293:1-8.

Hassett RP, and Crockett EL. 2009. Habitat temperature is an important determinant of cholesterol contents in copepods. Journal of Experimental Biology 212:71-77.

Hazel JR. 1995. Thermal adaptation in biological-membranes - is homeoviscous adaptation the explanation. Annual Review of Physiology 57:19-42.

Hazel JR, and Williams EE. 1990. The role of alterations in membrane lipid-composition in enabling physiological adaptation of organisms to their physical-environment. Progress in Lipid Research 29:167-227.

Hofmann GE, Buckley BA, Airaksinen S, Keen JE, and Somero GN. 2000. Heat-shock protein expression is absent in the Antarctic fish Trematomus bernacchii (family Nototheniidae). Journal of Experimental Biology 203:2331-2339.

Hsieh SL, and Kuo C-M. 2005. Stearoyl-CoA desaturase expression and fatty acid composition in milkfish (Chanos chanos) and grass carp (Ctenopharyngodon idella) during cold acclimation. Comparative biochemistry and physiology Part B, Biochemistry \& molecular biology 141:95101.

Hudson HA, Brauer PR, Scofield MA, and Petzel DH. 2008. Effects of warm acclimation on serum osmolality, cortisol and hematocrit levels in the Antarctic fish, Trematomus bernacchii. Polar Biology 31:991-997.

Iftikar FI, and Hickey AJR. 2013. Do mitochondria limit hot fish hearts? Understanding the role of mitochondrial function with heat stress in Notolabrus celidotus. PLoS ONE 8, e64120.

Iftikar FI, MacDonald JR, Baker DW, Renshaw GMC, and Hickey AJR. 2014. Could thermal sensitivity of mitochondria determine species distributions in a changing climate?

PeerJ reviewing PDF | (2017:11:21835:1:1:NEW 15 Apr 2018) 
589

590

591

Journal of Experimental Biology 217, 2348-2357.

Iftikar FI, Morash AJ, Cook DG, Herbert NA, and Hickey AJR. 2015. Temperature acclimation of mitochondria functions from the hearts of a temperate wrasse (Notolabrus celidotus). Comp.Biochem.Physiol. A Mol. Integr. Physiol. 184, 46-55. doi:10.1016/j.cbpa.2015.01.0

Jones GP. 1984. The influence of habitat and behavioural interactions on the local distribution of the wrasse, Pseudolabrus celidotus. Environmental Biology of Fishes 10:43-57.

Kock K-H. 2005. Antarctic icefishes (Channichthyidae): a unique family of fishes. A review, Part I. Polar Biology 28:862-895.

Lee MR F, and Tweed JK S. 2008. Isomerisation of cis-9 trans-11 conjugated linoleic acid (CLA) to trans-9 trans-11 CLA during acidic methylation can be avoided by a rapid base catalysed methylation of milk fat. Journal of Dairy Research 75:354-356.

Logue JA, de Vries AL, Fodor E, and Cossins AR. 2000. Lipid compositional correlates of temperatureadaptive interspecific differences in membrane physical structure. Journal of Experimental Biology 203:2105-2115.

Lowe CJ, and Davison W. 2005. Plasma osmolarity, glucose concentration and erythrocyte responses of two Antarctic nototheniid fishes to acute and chronic thermal change. Journal of Fish Biology 67:752-766.

Magalhaes BS, Fiamoncini J, Deschamps FC, Curi R, and Silva LP. 2010. Comparison of fatty acid composition in nine organs of the sympatric Antarctic teleost fish species Notothenia coriiceps and Notothenia rossii (Perciformes: Nototheniidae). Comparative Biochemistry and Physiology B-Biochemistry \& Molecular Biology 155:132-137.

Marr AG, and Ingraham JL. 1962. Effect of temperature on the composition of fatty acids in Escherichia coli. J Bacteriol 84:1260-1267.

Mayzaud P, Chevallier J, Tavernier E, Moteki M, and Koubbi P. 2011. Lipid composition of the Antarctic fish Pleuragramma antarcticum. Influence of age class. Polar Science 5:264-271.

Murray P, Hayward SAL, Govan GG, Gracey AY, and Cossins AR. 2007. An explicit test of the phospholipid saturation hypothesis of acquired cold tolerance in Caenorhabditis elegans. Proceedings of the National Academy of Sciences of the United States of America 104:5489-5494.

Murzina SA, Nefedova ZA, Falk-Petersen S, Ripatti PO, Ruokolainen TR, Pekkoeva SN, and Nemova NN. 2013. Lipid status of the two high latitude fish species, Leptoclinus maculatus and Lumpenus fabricii. Int J Mol Sci 14:7048-7060.

O'Grady SM, and DeVries AL. 1982. Osmotic and ionic regulation in polar fishes. Journal of Experimental Marine Biology and Ecology 57:219-228.

Palmerini CA, Mazzoni M, Giovinazzo G, and Arienti G. 2009. Blood lipids in Antarctic and in temperate-water fish species. J Membr Biol 230:125-131.

Paton CM, and Ntambi JM. 2009. Biochemical and physiological function of stearoyl-CoA desaturase. Am J Physiol Endocrinol Metab 297:E28-37.

Pilch PF, Thompson PA, and Czech MP. 1980. Coordinate Modulation of D-Glucose Transport Activity and Bilayer Fluidity in Plasma Membranes Derived from Control and Insulin-Treated Adipocytes. Proceedings of the National Academy of Sciences of the United States of America 77:915-918.

Podrabsky JE. 2009. Gene duplication underlies cold adaptation in Antarctic fish. Journal of Experimental Biology 212:v-vi.

Pörtner HO, Peck L, and Somero G. 2007. Thermal limits and adaptation in marine Antarctic ectotherms: an integrative view. Philosophical Transactions of the Royal Society B-Biological Sciences 362:2233-2258.

Römisch K, Collie N, Soto N, Logue J, Lindsay M, Scheper W, and Cheng C-HC. 2003. Protein translocation across the endoplasmic reticulum membrane in cold-adapted organisms. Journal of Cell Science 116:2875.

Sears B, and Ricordi C. 2011. Anti-Inflammatory Nutrition as a Pharmacological Approach to Treat Obesity. Journal of Obesity 2011:431985. 
640

Seki H, Tani Y, and Arita M. 2009. Omega-3 PUFA derived anti-inflammatory lipid mediator resolvin E1. Prostaglandins \& Other Lipid Mediators 89:126-130.

Skalli A, Robin JH, Le Bayon N, Le Delliou H, and Person-Le Ruyet J. 2006. Impact of essential fatty acid deficiency and temperature on tissues' fatty acid composition of European sea bass (Dicentrarchus labrax). Aquaculture 255:223-232.

Snyder RJ, Schregel WD, and Wei Y. 2012. Effects of thermal acclimation on tissue fatty acid composition of freshwater alewives (Alosa pseudoharengus). Fish Physiology and Biochemistry 38:363-373.

Somero G, and DeVries A. 1967. Temperature tolerance of some Antarctic fishes. Science 156:257 - 258.

Somero GN. 2010. The physiology of climate change: how potentials for acclimatization and genetic adaptation will determine 'winners' and 'losers'. Journal of Experimental Biology 213:912-920.

Strobel A, Graeve M, Poertner HO, and Mark FC. 2013. Mitochondrial Acclimation Capacities to Ocean Warming and Acidification Are Limited in the Antarctic Nototheniid Fish, Notothenia rossii and Lepidonotothen squamifrons. PloS one 8:e68865.

Trueman RJ, Tiku PE, Caddick MX, and Cossins AR. 2000. Thermal thresholds of lipid restructuring and Delta(9)-desaturase expression in the liver of carp (Cyprinus carpio L.). Journal of Experimental Biology 203:641-650.

Tukey N, and Davison W. 2004. Mode of locomotion places selective pressures on Antarctic and temperate labriform swimming fish. Comparative Biochemistry and Physiology, Part A 138 (2004) 391-398.

Usui K, Hiraki T, Kawamoto J, Kurihara T, Nogi Y, Kato C, and Abe F. 2012. Eicosapentaenoic acid plays a role in stabilizing dynamic membrane structure in the deep-sea piezophile Shewanella violacea: A study employing high-pressure time-resolved fluorescence anisotropy measurement. Biochimica et Biophysica Acta (BBA) - Biomembranes 1818:574-583.

Visentainer JV, Noffs MDA, de Oliveira Carvalho P, de Almeida VV, de Oliveira CC, and de Souza NE. 2007. Lipid Content and Fatty Acid Composition of 15 Marine Fish Species from the Southeast Coast of Brazil. Journal of the American Oil Chemists' Society 84:543-547.

Williams EE, and Hazel JR. 1995. Restructuring of plasma-membrane phospholipids in isolated hepatocytes of rainbow-trout during brief in-vitro cold-exposure. Journal of Comparative Physiology B-Biochemical Systemic and Environmental Physiology 164:600-608.

Yee JK, Mao CS, Hummel HS, Lim S, Sugano S, Rehan VK, Xiao G, and Lee WNP. Compartmentalization of stearoyl-coenzyme a desaturase 1 activity in HepG2 cells. Journal of Lipid Research. 2008; 49:2124-2134. doi: 10.1194/j1r.M700600-JLR20

Zelles L. 1997. Phospholipid fatty acid profiles in selected members of soil microbial communities. Chemosphere 35:275-294 


\section{Table $\mathbf{1}$ (on next page)}

Fish species sampled and collection location

* These fish were used for establishment of membrane lipid profiles (pre acclimation controls) and for thermal acclimation studies. 
1

\begin{tabular}{|l|l|l|c|}
\hline \multicolumn{1}{|c|}{ Fish species } & \multicolumn{1}{|c|}{ Family } & \multicolumn{1}{c|}{ Location } & $\begin{array}{c}\text { Adaptation } \\
\left.\text { Temperature( }{ }^{\circ} \mathbf{C}\right)\end{array}$ \\
\hline Trematomus bernacchii & Nototheniidae & McMurdoSound, Antarctica* & $-1-1.9$ \\
\hline Pagothenia borchgrevinki & Nototheniidae & McMurdoSound, Antarctica* & $-1-1.9$ \\
\hline Chionodraco hamatus & Channicthyidae & Terra Nova Bay, Antarctica & $-1-1.9$ \\
\hline Notolabrus celidotus & Labridae & Kaikoura, New Zealand & $9-13$ \\
\hline
\end{tabular}

2 


\section{Table 2 (on next page)}

Fatty acid composition of phospholipids in liver of Antarctic (CH, PB, TB) and nonAntarctic fish (NC) expressed as \% of total phospholipid fatty acids.

Values are mean \pm SEM $(n=4)$, except for Pagothenia borchgrevinki $(n=3)$, $n d=$ not detected.

Significant differences among the species for each particular fatty acid are indicated by different letter codes $(P<0.05) . \neq$ : Unidentified MUFA 
1

2

\begin{tabular}{|c|c|c|c|c|}
\hline & N. celidotus & C. hamatus & P. borchgreviniki & T. bernacchii \\
\hline C16:0 & $20.05 \pm 0.51^{a}$ & $20.43 \pm 0.69^{a}$ & $13.16 \pm 1.11^{b}$ & $13.08 \pm 0.52^{b}$ \\
\hline C18:0 & $12.64 \pm 1.16^{a}$ & $3.05 \pm 0.56^{b}$ & $4.16 \pm 0.64^{b}$ & $5.01 \pm 0.29^{b}$ \\
\hline$\sum$ SFA & $32.69 \pm 1.45^{a}$ & $23.47 \pm 0.40^{b}$ & $17.32 \pm 1.55^{c}$ & $18.09 \pm 0.68^{c}$ \\
\hline C16:1n7 & $0.48 \pm 0.48^{b}$ & $3.30 \pm 0.73^{a}$ & $4.01 \pm 0.41^{a}$ & $4.97 \pm 0.35^{a}$ \\
\hline C18:1n9 & $11.07 \pm 1.70$ & $10.51 \pm 1.99$ & $9.64 \pm 1.12$ & $7.42 \pm 0.28$ \\
\hline C18:1n7 & $3.22 \pm 0.50^{b}$ & $7.69 \pm 0.59^{a}$ & $9.84 \pm 0.74^{a}$ & $9.11 \pm 0.49^{a}$ \\
\hline C20:1n9 & nd & $5.04 \pm 0.98$ & $2.78 \pm 0.14$ & $3.62 \pm 0.38$ \\
\hline$C 20: 1^{\neq}$ & nd & $0.87 \pm 0.50$ & $2.93 \pm 1.83$ & $4.24 \pm 0.81$ \\
\hline ¿MUFA & $14.77 \pm 1.39^{b}$ & $27.40 \pm 1.98^{a}$ & $29.20 \pm 0.38{ }^{a}$ & $31.99 \pm 0.72^{a}$ \\
\hline C18:2n6 & $0.62 \pm 0.62$ & $1.17 \pm 0.41$ & nd & nd \\
\hline $\mathrm{C} 20: 4 \mathrm{n} 6$ & $9.08 \pm 0.50^{\mathrm{a}}$ & $4.97 \pm 0.35^{b}$ & $3.13 \pm 0.24^{b}$ & $4.79 \pm 0.33^{b}$ \\
\hline$C 20: 5 n 3$ & $14.00 \pm 0.75^{b}$ & $19.83 \pm 0.80^{a}$ & $22.52 \pm 1.92^{\mathrm{a}}$ & $19.63 \pm 1.08^{a}$ \\
\hline$C 22: 5 n 3$ & $1.41 \pm 0.47$ & nd & nd & nd \\
\hline$C 22: 6 n 3$ & $28.06 \pm 1.53^{a}$ & $20.84 \pm 1.44^{\mathrm{b}}$ & $23.54 \pm 1.36^{\mathrm{ab}}$ & $25.50 \pm 0.32^{\mathrm{ab}}$ \\
\hline$\sum$ PUFA & $53.16 \pm 1.96^{a}$ & $46.80 \pm 1.13^{b}$ & $49.18 \pm 0.50^{\mathrm{ab}}$ & $49.91 \pm 0.73^{a b}$ \\
\hline
\end{tabular}




\section{Table 3(on next page)}

Fatty acid composition of phospholipids in the liver of Trematomus bernacchii (14 days acclimation) and Pagothenia borchgrevinki (28 days acclimation) acclimated at $0{ }^{\circ} \mathrm{C}$ and $4{ }^{\circ} \mathrm{C}$.

Values are mean \pm SEM $(n=4)$ and expressed in $\%$ of total phospholipid fatty acids.Significant effects of thermal acclimation are indicated by asterisks $(P<0.05) . \neq$ : Unidentified MUFA 


\begin{tabular}{|c|c|c|c|c|c|c|}
\hline & \multicolumn{3}{|c|}{ Trematomus bernacchii } & \multicolumn{3}{|c|}{ Pagothenia borchgrevinki } \\
\hline & TO & T4 & P-value & TO & T4 & P-value \\
\hline C16:0 & $16.01 \pm 0.76$ & $14.30 \pm 0.53$ & 0.13 & $13.79 \pm 1.00$ & $14.18 \pm 0.34$ & 0.74 \\
\hline C18:0 & $6.49 \pm 0.30$ & $7.71 \pm 0.47$ & 0.08 & $5.33 \pm 0.86$ & $4.20 \pm 0.37$ & 0.29 \\
\hline$\Sigma$ SFA & $22.50 \pm 1.00$ & $22.01 \pm 0.54$ & 0.69 & $19.12 \pm 1.5$ & $18.38 \pm 0.58$ & 0.67 \\
\hline C16:1n7 & $4.42 \pm 0.78$ & $3.09 \pm 0.47$ & 0.22 & $3.66 \pm 0.38$ & $4.17 \pm 0.53$ & 0.47 \\
\hline $\mathrm{C} 16: 1^{\neq}$ & $2.44 \pm 0.87$ & $2.68 \pm 0.11$ & 0.81 & $0.43 \pm 0.43$ & $1.81 \pm 0.67$ & 0.15 \\
\hline C18:1n9 & $5.68 \pm 0.26$ & $5.98 \pm 0.87$ & 0.76 & $10.05 \pm 0.68$ & $11.27 \pm 0.32$ & 0.18 \\
\hline C18:1n7 & $8.55 \pm 0.23$ & $9.03 \pm 0.83$ & 0.61 & $9.50 \pm 0.50$ & $9.69 \pm 0.39$ & 0.78 \\
\hline C20:1n9 & $3.07 \pm 0.27$ & $3.26 \pm 0.31$ & 0.66 & $2.11 \pm 0.20$ & $2.05 \pm 0.23$ & 0.86 \\
\hline$C 20: 1^{\neq}$ & $1.93 \pm 1.20$ & $2.83 \pm 1.10$ & 0.59 & $0.72 \pm 0.72$ & $1.17 \pm 0.70$ & 0.67 \\
\hline$\sum$ MUFA & $26.08 \pm 1.20$ & $26.87 \pm 1.00$ & 0.64 & $26.47 \pm 0.83$ & $30.15 \pm 1.40$ & 0.09 \\
\hline C20:4n6 & $4.75 \pm 0.73$ & $4.68 \pm 0.34$ & 0.94 & $2.56 \pm 0.10$ & $3.49 \pm 0.36$ & 0.09 \\
\hline C20:5n3 & $24.24 \pm 1.10$ & $19.05 \pm 0.72$ & $0.01^{*}$ & $18.40 \pm 1.30$ & $17.64 \pm 2.00$ & 0.76 \\
\hline$C 22: 6 n 3$ & $22.43 \pm 0.64$ & $27.38 \pm 0.93$ & $0.01^{*}$ & $29.51 \pm 2.90$ & $30.35 \pm 3.20$ & 0.85 \\
\hline $\begin{array}{l}\text { ¿PUFA } \\
\text { DSI (Desaturase }\end{array}$ & $51.42 \pm 2.00$ & $51.11 \pm 0.55$ & 0.89 & $50.47 \pm 2.30$ & $51.47 \pm 1.50$ & 0.73 \\
\hline C16:1n7/C16:0 & $0.27 \pm 0.04$ & $0.21 \pm 0.03$ & 0.24 & $0.27 \pm 0.02$ & $0.30 \pm 0.04$ & 0.564 \\
\hline C18:1n9/C18:0 & $0.88 \pm 0.06$ & $0.78 \pm 0.11$ & 0.46 & $2.11 \pm 0.52$ & $2.76 \pm 0.31$ & 0.341 \\
\hline
\end{tabular}


Figure 1

PCA plot of the contribution of the phospholipid fatty acids to the principal components in liver tissue of the Antarctic species and non-Antarctic species.

Antarctic species $C$. hamatus (CH), P. borchgrevinki (PB), and T. bernacchii (TB) and the nonAntarctic species N. celidotus (NC).

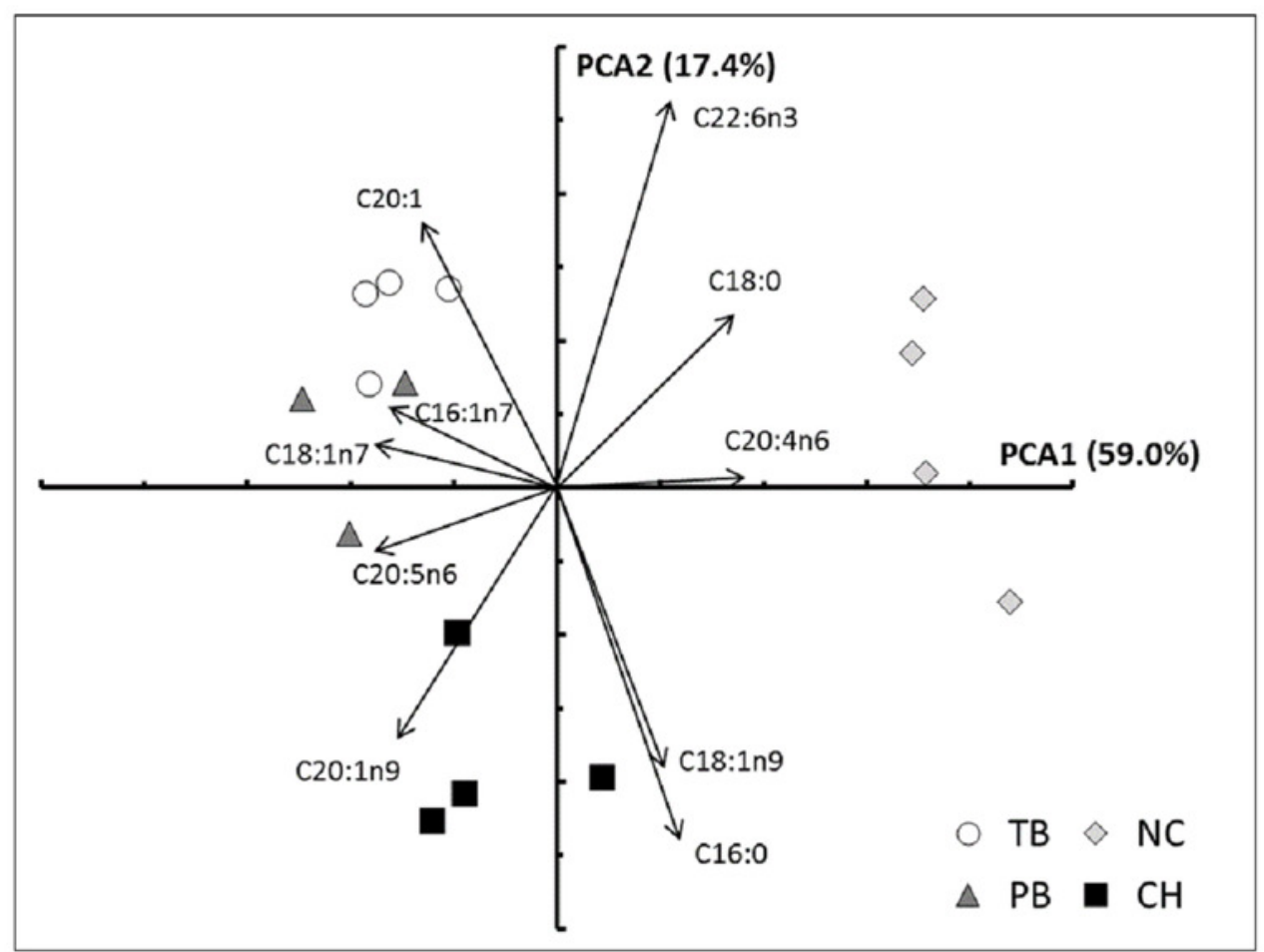




\section{Figure 2}

Membrane Cholesterol concentration in the livers of Antarctic species $C$. hamatus $(\mathrm{CH})$, $P$. borchgrevinki (PB), T. bernacchii (TB) and non-Antarctic species Notolabrus celidotus (NC).

Values are mean \pm SEM $(n=4)$. Significant effects among species are indicated by different letters $(P<0.05)$.

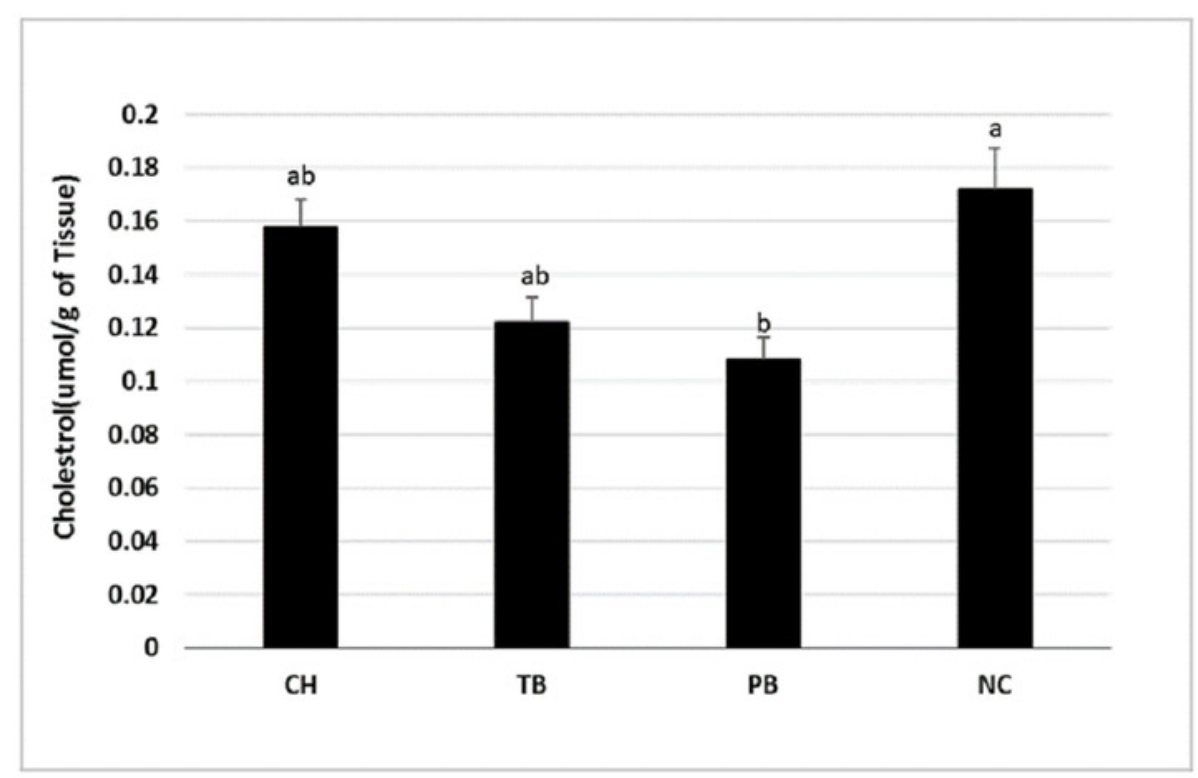




\section{Figure 3}

Effect of thermal acclimation on membrane cholesterol concentration in the livers of T.bernacchii (TB) and P.borchgrevinki (PB).

Membrane cholesterol was determined 14 days after thermal acclimation in TB and 28 days in PB. Values are means \pm SEM $(n=4)$ for control temperature $\left(T 0: 0^{\circ} \mathrm{C}\right)$ and warm $\left(T 4: 4^{\circ} \mathrm{C}\right)$ acclimation.

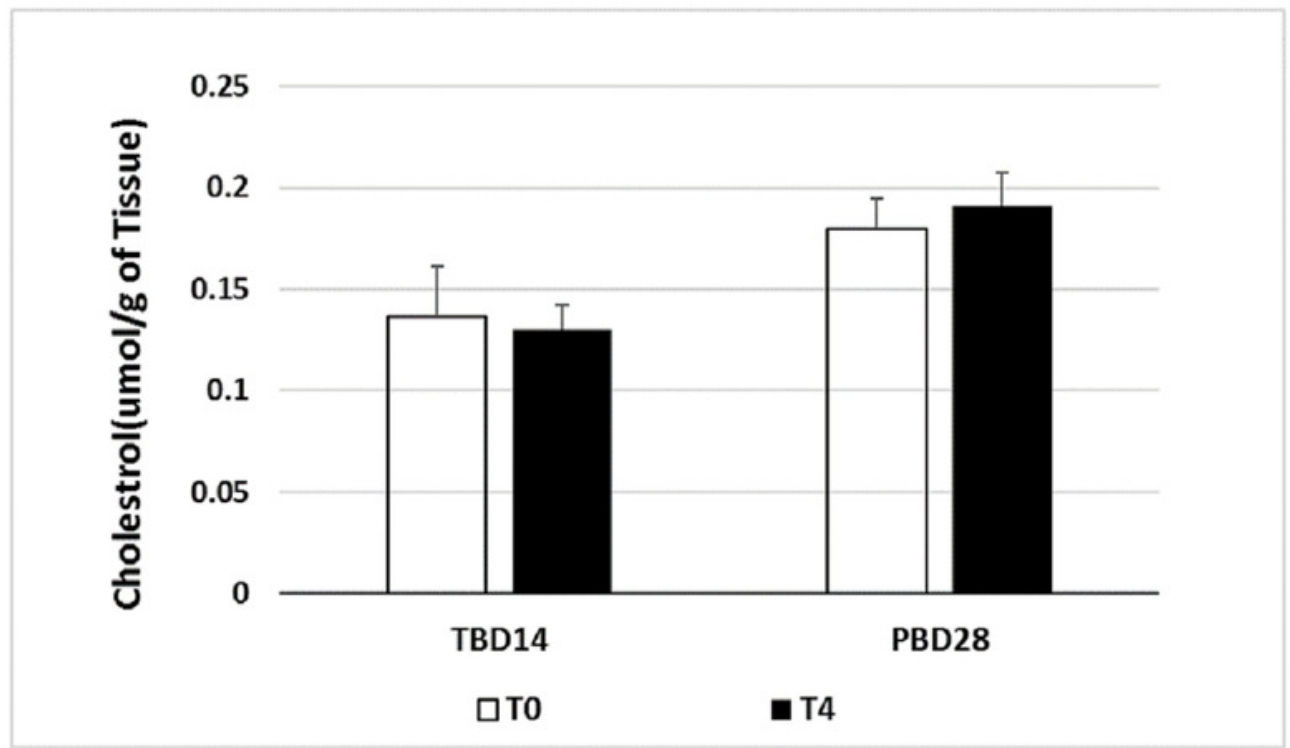


Figure 4

Plasma osmolality determined at various time points. A. In T.bernacchii (TB). B. In P.borchgrevinki (PB).

Plasma osmolality was determined 14 days after thermal acclimation in TB (A) and 28 days in $\mathrm{PB}(\mathrm{B})$. Days after thermal acclimation D1, D2, D3, D7, D14 and D28 at $4{ }^{\circ} \mathrm{C}(\mathrm{T} 4)$ and the control temperature of $0{ }^{\circ} \mathrm{C}(\mathrm{TO})$. Values are $\pm \operatorname{SEM}(n=4)$. Significant effects of the interaction of thermal acclimation and days of acclimation are indicated by different letters.

A

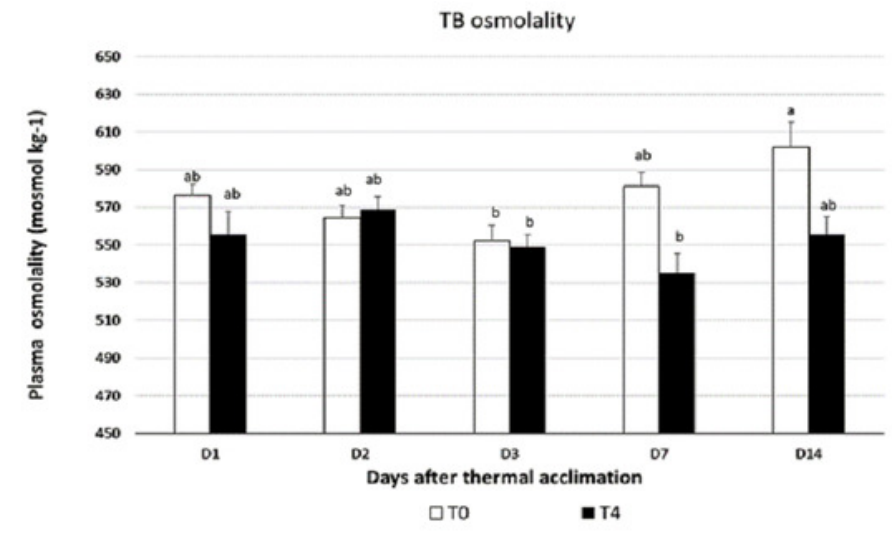

B

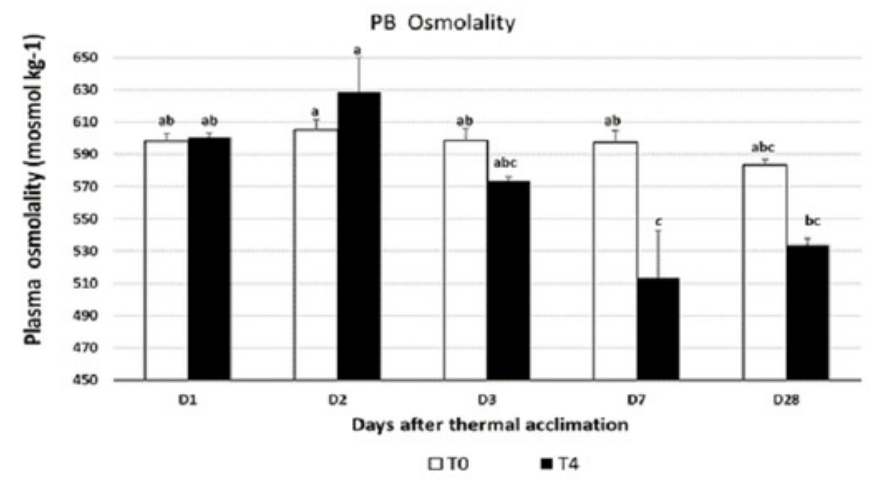


Figure 5

Phospholipid profile of $T$. bernacchii (TB) in liver after 7 days (D7) of thermal acclimation at $6{ }^{\circ} \mathrm{C}$.

Values are means $\pm \operatorname{SEM}(n=4)$ for control temperature $\left(\mathrm{T0:} 0^{\circ} \mathrm{C}\right)$ and warm $\left(\mathrm{T} 6: 6^{\circ} \mathrm{C}\right)$ acclimation $(n=3)$. Significant effects of thermal acclimation are indicated by asterisks $(\mathrm{P}<0.05)$.

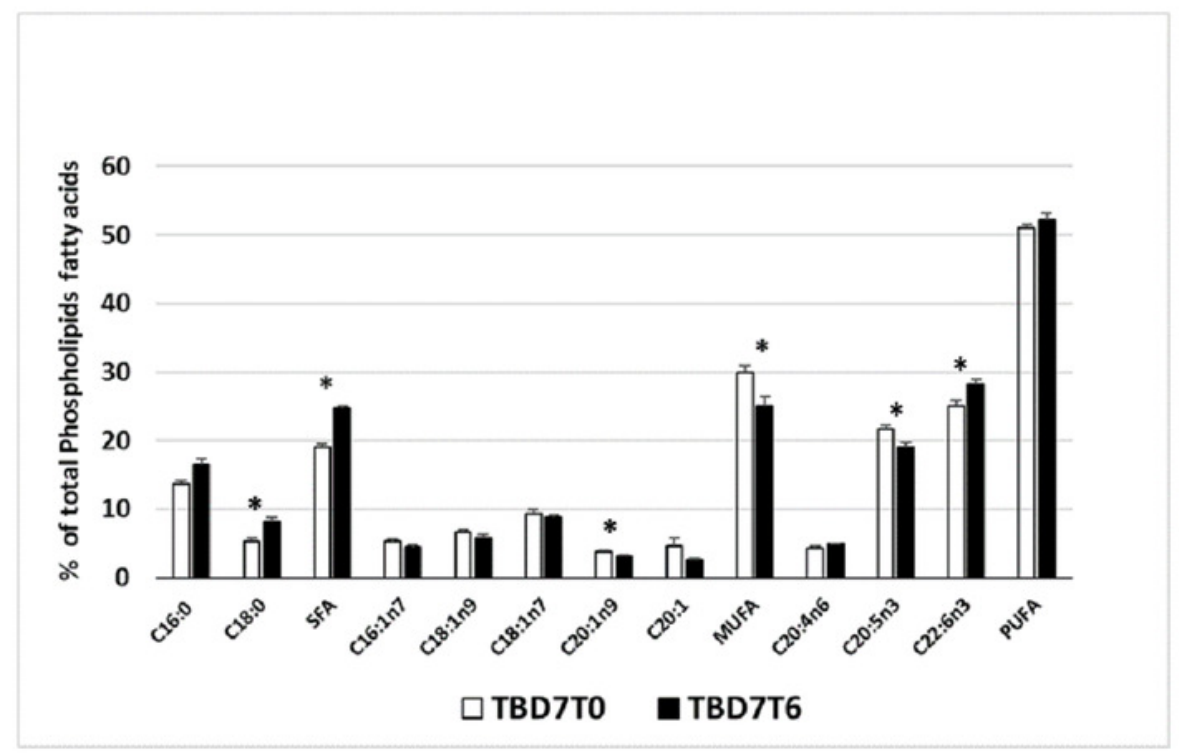


Figure 6

Phospholipid profile of $P$. borchgreviniki (PB) in liver after 7 days (D7) of thermal acclimation at $6{ }^{\circ} \mathrm{C}$.

Values are means \pm SEM $(n=4)$ for control temperature $\left(T 0: 0{ }^{\circ} \mathrm{C}\right)$ as well as warm $\left(\mathrm{T6:} 6{ }^{\circ} \mathrm{C}\right)$ acclimation. Significant effects of thermal acclimation are indicated by asterisks $(P<0.05)$.

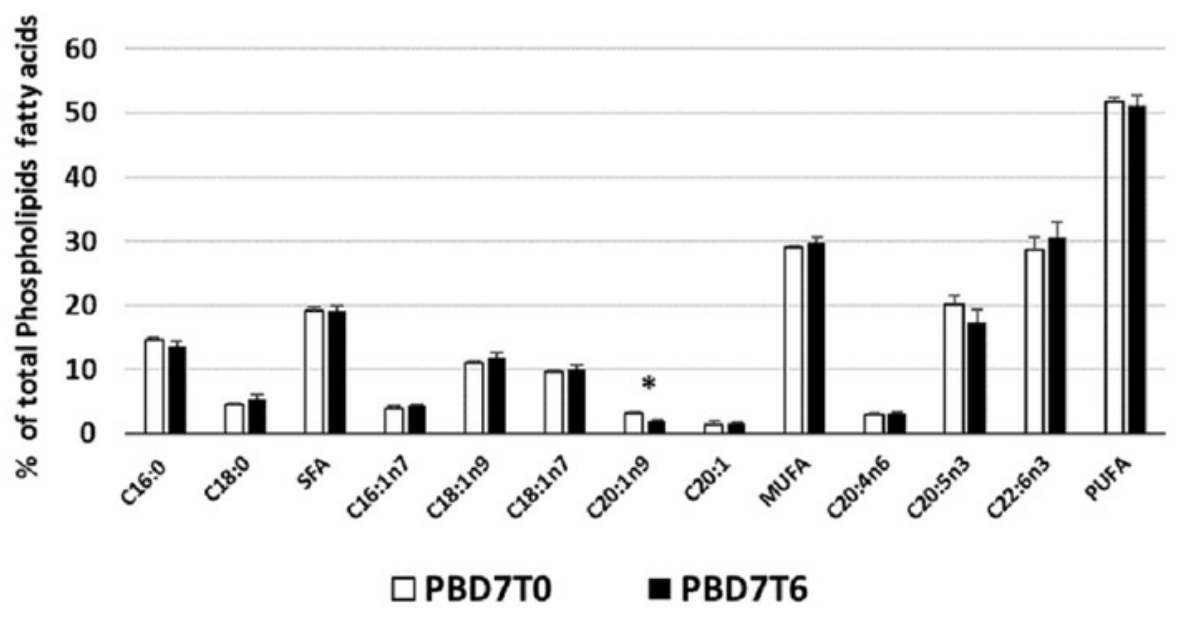




\section{Figure 7}

Desaturase Index in livers of Antarctic species C. hamatus (CH), P. borchgrevinki (PB), and $T$. bernacchii (TB) and the non-Antarctic species $N$. celidotus(NC). A.Desaturase index (C16:1n7/C16:0). B. Desaturase index (C18:1n9/C18:0)

Values are mean $\pm \operatorname{SEM}(n=4)$. Significant effects among species are indicated by different letters $(P<0.05)$.

A

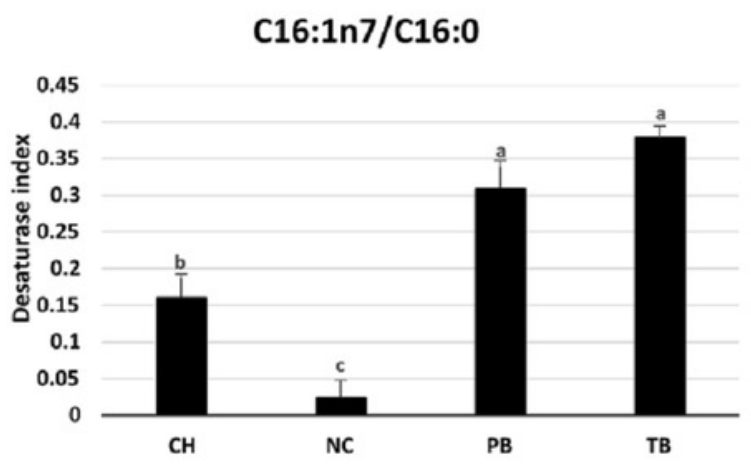

B C18:1n9/C18:0

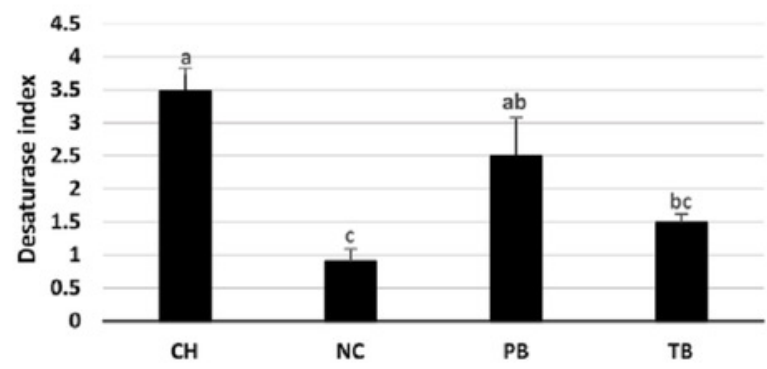


Figure 8

Changes in the Desaturase Index in the livers of $P$. borchgrevinki (PB) and $T$. bernacchii (TB) acclimated at $6{ }^{\circ} \mathrm{C}$ for 7 days. A.Desaturase index (C16:1n7/C16:0). B. Desaturase index (C18:1n9/C18:0).

Values are means \pm SEM $(n=4)$ for control temperature $\left(T 0: 0{ }^{\circ} \mathrm{C}\right)$ as well as warm $\left(\mathrm{T6:} 6{ }^{\circ} \mathrm{C}\right)$ acclimation. Significant effects of thermal acclimation are indicated by asterisks $(P<0.05)$.

A

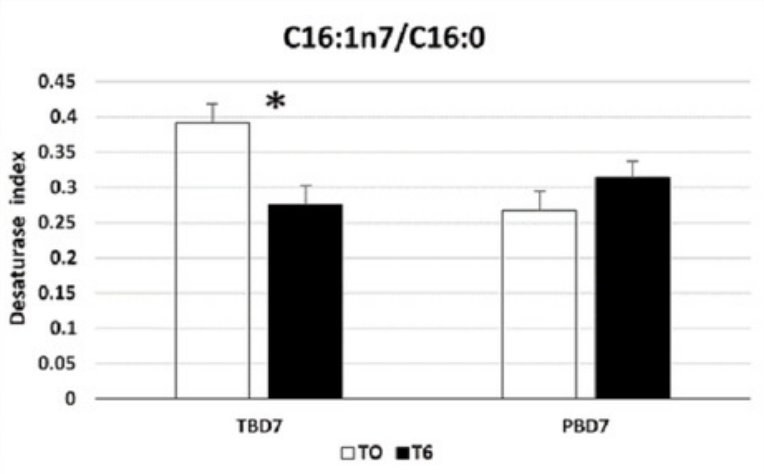

B

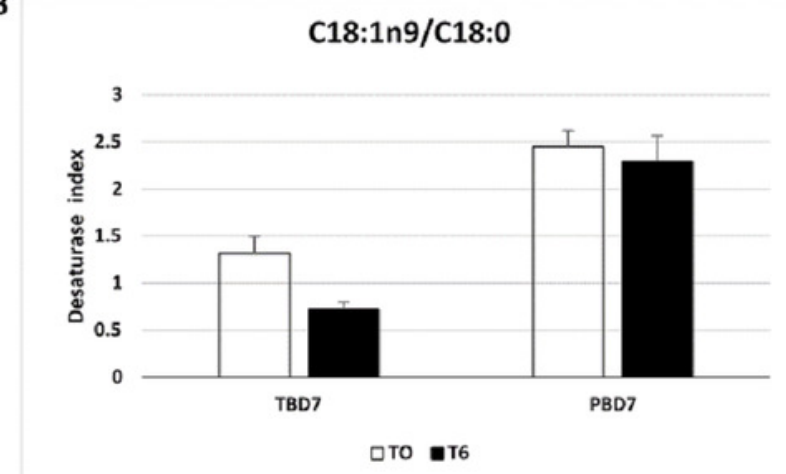

